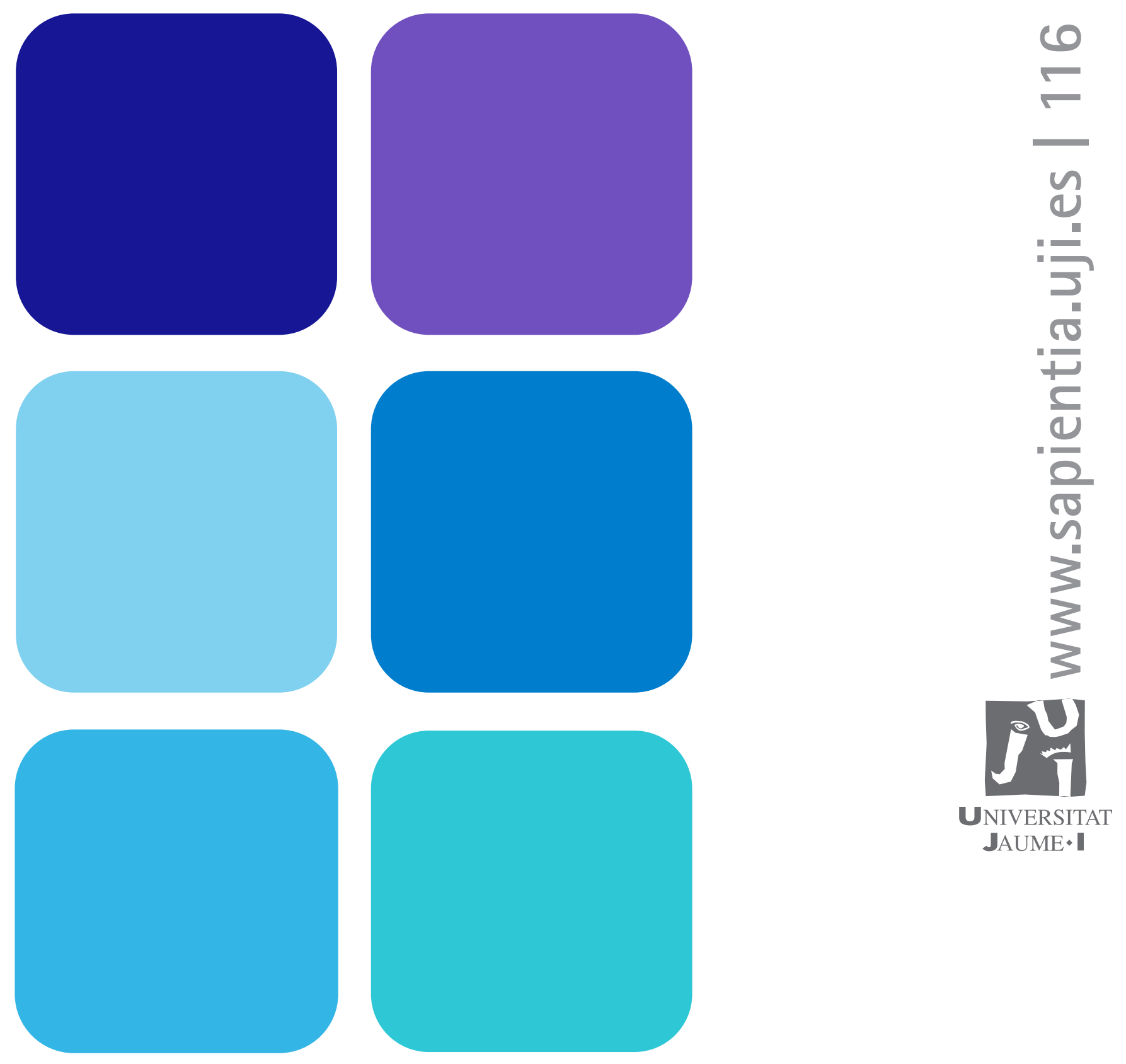

Teoría de programación
de radio y televisión 


\section{Teoría de programación de radio y televisión}

Jéssica Izquierdo Castillo

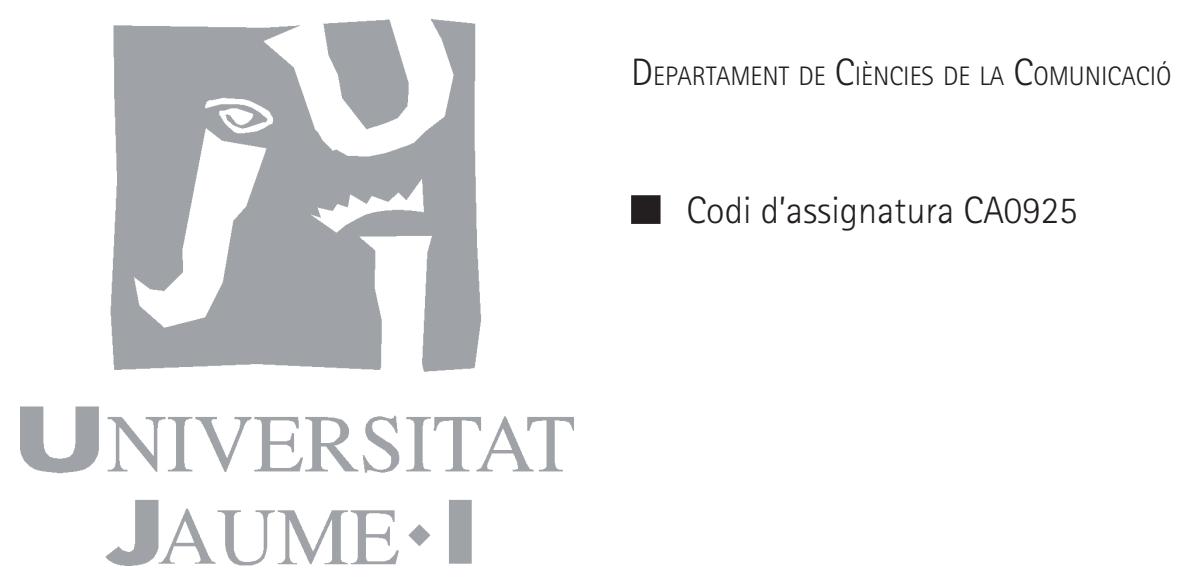


Edita: Publicacions de la Universitat Jaume I. Servei de Comunicació i Publicacions Campus del Riu Sec. Edifici Rectorat i Serveis Centrals. 12071 Castelló de la Plana http://www.tenda.uji.es e-mail: publicacions@uji.es

Col·lecció Sapientia 116

www.sapientia.uji.es

Primera edició, 2016

ISBN: 978-84-16356-91-1

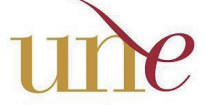

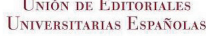

Publicacions de la Universitat Jaume I és una editorial membre de l'UNE, cosa que en garanteix la difusió de les obres en els àmbits nacional i internacional. www.une.es

\section{cc) (†) ()}

Reconeixement-CompartirIgual

CC BY-SA

Aquest text està subjecte a una llicència Reconeixement-CompartirIgual de Creative Commons, que permet copiar, distribuir i comunicar públicament l'obra sempre que s'especifique l'autoria i el nom de la publicació fins i tot amb objectius comercials i també permet crear obres derivades, sempre que siguen distribuïdes amb aquesta mateixa llicència. http://creativecommons.org/licenses/by-sa/3.0/legalcode

Aquest llibre, de contingut cientific, ha estat avaluat per persones expertes externes a la Universitat Jaume I, mitjançant el mètode denominat revisió per iguals, doble cec. 


\section{ÍNDICE}

Bloque 1. Introducción a la programación

1.1. Definición de programación mediática

1.2. La figura del programador

1.3. Historia de la programación

1.3.1. Origen de la programación radiofónica

1.3.2. Origen de la programación televisiva

1.3.3. El impacto de la desregulación

Bloque 2. Modelos, procesos y técnicas de programación

2.1. Modelos de programación

2.1.1. Modelo público de programación

2.1.2. Modelo privado de programación

2.1.3. Modelo generalista de programación

2.1.4. Modelo temático de programación

2.1.5. Modelo gratuito de programación

2.1.6. Modelo de pago de programación

2.2. El proceso de construcción de la parrilla de programación

2.3. Las estrategias y técnicas de programación

Bloque 3. Los públicos y la investigación de audiencias

3.1. La investigación de audiencias.

3.2. Los índices de audiencias

3.3. La audiencia y la publicidad

3.4. La audimetría

3.5. Ventajas y limitaciones de la audimetría

Bloque 4. Géneros y formatos de radio y televisión.

Tendencias en el mercado español

4.1. Definición de género

4.1.1. Definiciones de género radiofónico

4.1.2. Definiciones de género televisivo

4.2. Géneros televisivos

4.2.1. Géneros de la Información

4.2.2. Géneros de Ficción

4.2.3. Géneros de Entretenimiento

4.3. Géneros radiofónicos

4.3.1. Programas informativos

4.3.2. Programas deportivos 
4.3.3. Programas dramáticos

4.3.4. Programas musicales

4.3.5. Programas de participación de la audiencia

4.3.6. Programas magazine

4.4. Transformación y evolución de los géneros.

4.5. Géneros publicitarios para radio y televisión

4.5.1. Géneros publicitarios para radio

4.5.2. Géneros publicitarios para televisión

Bloque 5. Marco legal para la programación

Bibliografía 
Esta guía didáctica tiene como principal objetivo servir a los/as estudiantes del Grado en Comunicación Audiovisual para el seguimiento, preparación y desarrollo de la asignatura de Teoría y Técnica de Programación de Radio y Televisión.

La digitalización, junto con el proceso de convergencia mediática, han provocado una serie de cambios que afectan a los medios de comunicación en diferentes niveles. Uno de los principales está relacionado con los contenidos audiovisuales, en tanto que representan el objeto final del funcionamiento de los medios.

La asignatura plantea la conceptualización y análisis de la programación de los medios audiovisuales y de su evolución histórica. Para ello, presta atención tanto al estudio crítico de los conceptos teóricos, como a la praxis específica de la programación radiofónica y televisiva. Se introducirán el concepto e historia de la programación, así como los públicos y audiencias audiovisuales. Se abordarán las técnicas y estrategias que determinan la configuración de las parrillas de programación en dichos medios, y se estudiarán los diferentes géneros y formatos. Se analizará el contexto actual del mercado audiovisual español en materia de programación, se presentará el marco legal que afecta a los contenidos de radio y televisión, y finalmente se motivará la reflexión crítica sobre las últimas tendencias de programación audiovisual. 


\section{Bloque 1}

\section{Introducción}

a la programación

\subsection{Definición de programación mediática}

A pesar de lo significativo de los cambios tecnológicos, la radio y la televisión continúan funcionando bajo los parámetros del sistema tradicional. Esta publicación aporta una guía de estudio de la radio y la televisión desde la perspectiva de la programación de contenidos, que explique de qué manera se constituye la concepción de estos medios en base al servicio de difusión.

A partir del conocimiento de la radio y la televisión en su entorno tradicional, se estará en disposición de comprender mejor los cambios que deben enfrentar en el escenario convergente, donde los contenidos se mueven desprovistos de su contexto mediático y, por tanto, obligan a repensar los parámetros tradicionales de configuración de la oferta programática.

Por otro lado, a pesar de la proliferación y auge de medios y consumo digitales, la radio y la televisión clásicas continúan registrando unos índices estables de audiencia, según muestra el gráfico 1.

Gráfico 1. Evolución de la audiencia de radio y televisión en España

EVOLUCIÓN (Penetración \%)

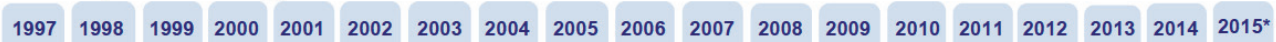

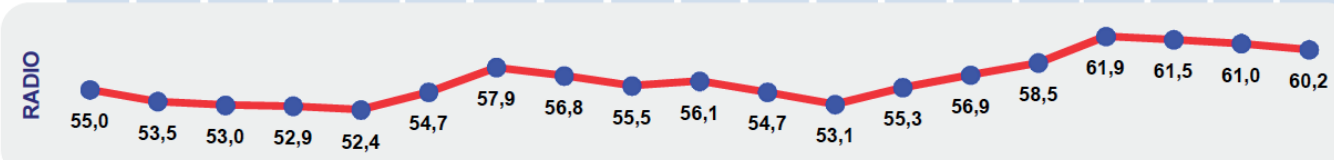

EVOLUCIÓN (Penetración \%)

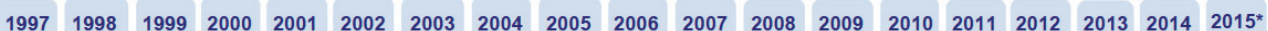

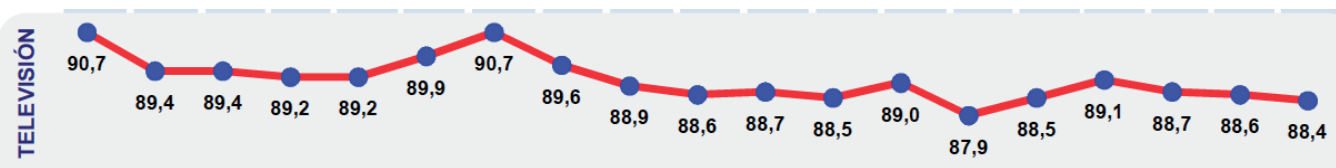

Fuente: EGM, 2015 
Con el fin de abordar una definición de la programación mediática, es necesario partir de la base comunicativa que supone el acto de programar. Arana (2011) realiza un ejercicio de adaptación del esquema de la comunicación (Lasswell, 1948; Shannon y Weaver, 1949) al contexto mediático de la televisión que aquí hacemos extensible también al medio radiofónico. De esta forma, intenta exponer la complejidad de un proceso comunicativo aparentemente sencillo, que deriva en cinco esquemas diferentes en la articulación comunicativa de la programación.

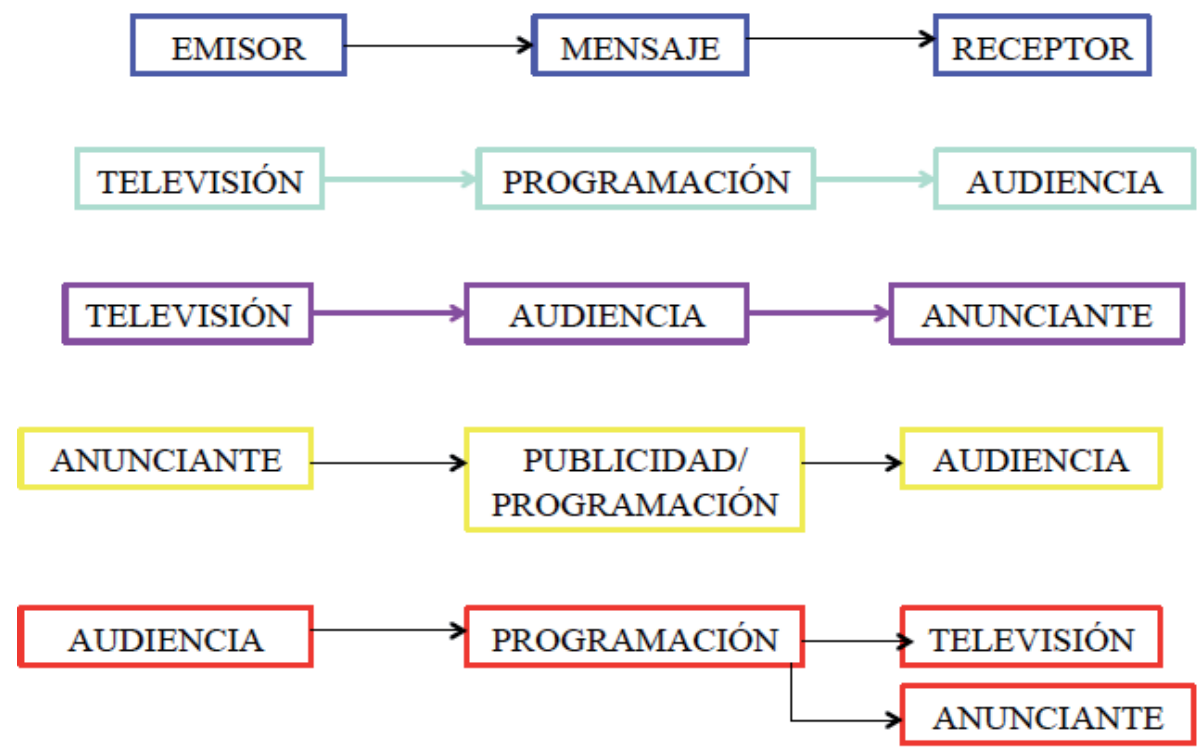

Estos esquemas responden a la combinación de los actores intervinientes en el proceso comunicativo de programación:

1. Esquema básico del proceso comunicativo (Lasswell, 1948 y Weaver\&Shannon, 1949).

2. Esquema con la programación como elemento central.

3. Esquema con la audiencia como elemento en compra-venta.

4. Esquema basado en el trueque.

5. Esquema con la audiencia como agente motriz.

Esta diversidad de enfoques responde a la naturaleza del medio de comunicación como industria, con la particularidad de que trabaja en un mercado doble. Por un lado, ofrece contenidos a las audiencias. Por otro, ofrece audiencias a los anunciantes. Si trazamos un esquema de las relaciones entre estos actores básicos que intervienen en la programación, debemos considerar la estructura básica del proceso, donde el medio de comunicación actúa en un doble mercado, mutuamente interdependiente. Así, un primer mercado liga al medio con su audiencia, mientras que el segundo se dirige al anunciante. La conexión entre estos tres actores básicos se produce cuando se conecta la audiencia con el anunciante. Por tanto, el medio ofrece contenido a la audiencia para que elija su cadena, mientras que la audiencia actúa como valor de reclamo para la venta de acciones publicitarias (spots, cuñas, patrocinios, etc.). 


\section{MEDIO DE COMUNICACIÓN}

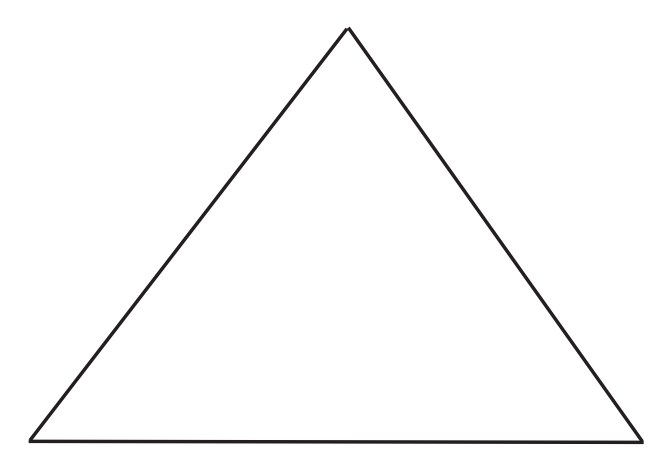

AUDIENCIA

ANUNCIANTE

La programación como fenómeno ha sido considerado por diferentes autores, aunque pocos han abordado el estudio en profundidad. Arana (2011) realiza una recopilación de las principales definiciones relacionadas con el fenómeno, atendiendo a una clasificación de conceptualizaciones. Así, la programación puede ser entendida como un discurso comunicativo, pero también como un producto, un proceso de ordenación programada, el resultado de un proceso contractual o la unidad discursiva de cada emisora.

1. La programación como un discurso:

En el eje comunicativo, la programación constituiría el mensaje que el medio crea para la audiencia. Se puede considerar también como un macrodiscurso de significado global que, a su vez, acoge diferentes partes con significado individual. Para elaborar este macrodiscurso, las cadenas utilizan diferentes elementos que le dotan de continuidad y estilo propio, desde los recursos técnico-expresivos, como promos, caretas, elementos gráficos y cortinillas, hasta distintivos propios en las presentaciones de contenido, un estilo propio en el tratamiento de formatos; e incluso abarca la línea editorial, el modelo estratégico y las bases fundacionales de la cadena.

La programación televisiva constituye una unidad discursiva por encima de las unidades particulares que la integran. La programación hilvana una complejidad de microdiscursos constituidos por los programas con su unidad parcial y los recursos de unión y continuidad que permiten pasar y diferenciar unos de otros. La acción de la programación es introducir la coherencia necesaria para que se comprenda como una continuidad y como una expresión global de la entidad enunciadora. (Cebrián, 1998: 379)

2. La programación como producto:

La programación entendida como producto es resultado de considerar los programas y su gestión como elemento resultante de una industria audiovisual. Esta industria es compleja y requiere de una elevada cualificación, que exige un conocimiento en profundidad del mercado audiovisual. Esto abarca también la legislación aplicable al sector, el conocimiento de la situación financiera, la actividad de la competencia, las pautas de consumo de la audiencia, formas alternativas de ocio, etc. 


\section{Enfatizan la idea de programación:}

Diversos autores han señalado la función de ordenación programada, a partir de la selección, aplicación de normas y acciones y secuencialización:

La selección de los diferentes programas estableciendo un orden de paso. (Westphalen y Piñuel, 1993: 1093)

La suma de reglas o procedimientos de los que se sirve el programador para ordenar adecuadamente en el tiempo y en el espacio las distintas unidades programáticas o programas. (Benito, 1991: 1118)

Idear y ordenar las acciones necesarias para realizar la programación de una emisora de televisión, con indicación de las partes de que se ha de componer y lo que ha de integrar cada una de ellas. (De la Mota, 1988: 216 del II tomo)

La práctica de colocar, según una cierta secuencia, programas de una cierta duración en la rejilla de una emisora (Palacio, 1989: 38)

4. Enfatizan la idea contractual entre emisora y público:

También destaca la contextualización del fenómeno en la relación implícita que el medio establece con su audiencia, y que pauta las decisiones y acciones programáticas. A partir de una relación continuada, el medio va conformando unas rutinas que generan en la audiencia una serie de expectativas frente a la oferta de la cadena o emisora.

La necesidad básica de una estación de televisión, que consiste en llenar de contenidos todas las horas previstas de emisión. (Soler, 1988: 127)

No son solo los programas y los géneros, sino fundamentalmente su ubicación temporal, de acuerdo con las audiencias potenciales conocidas de cada rejilla horaria y los objetivos de cada emisora. (Bustamante y Zallo, 1988: 138)

La distribución de unos tiempos en función de unos recursos. (Faus, 1995: 191)

La adecuación de unos contenidos en forma de programas a una audiencia potencial» o «el conjunto variado de posibilidades ofrecidas para el visionado, durante el tiempo dedicado a dicha actividad. (Cortés, 1989: 32)

Básicamente, la parrilla de programación es la ordenación de los programas para cada día, semana va y semana viene. Crear un marco de referencia que le resulta familiar a la audiencia y al que puede recurrir cada semana si quiere ver un programa concreto, a una hora determinada. Uno de los aspectos que debe considerar el programador es el de hacer coincidir las audiencias potenciales de cada franja horaria con la oferta de programas - construyendo audiencia o respondiendo a sus necesidades depende del punto de vista-. (Paterson, 1990: 31)

\section{Unidad discursiva para cada emisora:}

En última instancia, la programación supone una acción comunicativa, una unidad discursiva en si misma, con identidad global, pero también como suma de discursos individuales. 
Es la unificadora de las estructuras autónomas, ya que la televisión presenta un conjunto de programas unidos, vinculados, de alguna forma unos con otros, con un ritmo propio y con unas leyes específicas. De este modo es la continuidad de la emisión la que permite hablar de programación más que de programas en concreto. (Cebrián, 1978: 250)

Es la labor de coordinar, concatenar y unir diferentes espacios televisivos de distintos géneros y duraciones irregulares para formar un todo único y con sentido exclusivo de personalidad propia en la idea y concepto fundacional de la cadena. (Vaca, 1997: 471)

Si los programas son los ladrillos con los que se construye la televisión, la programación es su arquitectura, la que define el edificio y da sentido a cada uno de los ladrillos. (Ellis, 2000)

[...] la profesión del programador televisivo se entiende como la práctica de colocar programas, según una cierta secuencia, en la parrilla de una emisora. Un segundo escalón o nivel [...] recogería en sus enunciados las labores de selección, coordinación y ordenación de programas de una cierta duración en una estructura determinada; o, desde otra perspectiva, la búsqueda de un adecuado correlato entre unos programas y la audiencia potencial en un momento dado. (Contreras y Palacio, 2001: 27)

A partir de estas conceptualizaciones, podemos avanzar en la definición de programación y observamos que el estudio del fenómeno afecta a múltiples dimensiones. La programación posee una vertiente industrial, profesional y económica, pero, al mismo tiempo, posee un innegable componente de comunicación entre emisor y audiencia. En su estudio, por tanto, no solo se contemplan aspectos económicos y sociales, sino también aquellos vinculados con los efectos psicosociales que produce. Es importante, por tanto, entender la programación como un diálogo entre programadores y audiencia. No se basa en una comunicación unilateral e impuesta, sino que tiene la audiencia como cómplice del proceso. Además, la programación, como hemos visto, no solo se entiende como un mero ensamblaje de espacios y programas, sino como un sistema, como una estructura de múltiples factores. Para diferenciar entre ambas dimensiones, resulta útil la diferenciación de los vocablos ingleses Schedule y Programme. Mientras Schedule se refiere a la catalogación del orden de programas en una secuencia, Programme abarca acciones de planificación, formación y trazado del plan o proyecto. En este sentido, incluye muchas de las actividades de fundamento económico en el funcionamiento de las empresas. En la acepción española, programar, se pierde esta gradación en el significado del concepto. Además, en España, como en el resto de Europa, no existe diferenciación lingüística entre funciones de programador/a pues, en líneas generales, durante décadas el/la programador/a europeo ha desarrollado un trabajo subordinado a directrices ajenas, asumiendo básicamente las funciones de elaboración de la parrilla y ensamblaje de programas.

Finalmente, podemos concluir que la programación es un fenómeno complejo que debe considerar múltiples factores y dimensiones en un contexto comunicativo con relaciones y obligaciones con su audiencia. Arana lo expone de manera completa en esta tabla (2011:74): 


\begin{tabular}{|l|l|l|}
\hline \multicolumn{1}{|c|}{ EMISOR } & \multicolumn{1}{c|}{ MENSAJE } & \multicolumn{1}{c|}{ RECEPTOR } \\
\hline $\begin{array}{l}\text { Legislación sobre } \\
\text { el audiovisual }\end{array}$ & $\begin{array}{l}\text { Accesibilidad } \\
\text { de los distintos programas }\end{array}$ & Hábitos sociales \\
\hline $\begin{array}{l}\text { Legislación sobre } \\
\text { la publicidad }\end{array}$ & $\begin{array}{l}\text { Tipo de parrilla } \\
\text { de programación }\end{array}$ & Consumo de televisión \\
\hline $\begin{array}{l}\text { Normativa técnica aplicada } \\
\text { a la emisión }\end{array}$ & $\begin{array}{l}\text { Actividad } \\
\text { de la competencia }\end{array}$ & Equipamiento \\
\hline $\begin{array}{l}\text { Situación socio-política } \\
\text { del sistema televisivo }\end{array}$ & Coste & Gustos/modas \\
\hline $\begin{array}{l}\text { Cobertura geográfica } \\
\text { de la señal }\end{array}$ & $\begin{array}{l}\text { Estacionalidad, horario, } \\
\text { fecha y duración }\end{array}$ & $\begin{array}{l}\text { Consideración social } \\
\text { del medio }\end{array}$ \\
\hline Financiación & Atractivo publicitario & Ideología \\
\hline $\begin{array}{l}\text { Criterios ideológicos/ } \\
\text { filosóficos del canal }\end{array}$ & Contenidos y formatos & $\begin{array}{l}\text { Perfil } \\
\text { sociodemográfico }\end{array}$ \\
\hline $\begin{array}{l}\text { Número y características } \\
\text { de los distintos canales }\end{array}$ & Ciclo vital de programa & $\begin{array}{l}\text { Actividad } \\
\text { de la competencia }\end{array}$ \\
\hline Recursos productivos & Definición del canal & Actualidad \\
\hline Presupuesto & & \\
\hline Contratos, derechos... & & \\
\hline
\end{tabular}

\subsection{La figura del programador}

La figura del programador ha evolucionado en España, y en Europa, con rapidez, a partir de dos fenómenos: la desregulación y la mercantilización del sistema audiovisual. La aparición de la televisión privada puso de manifiesto una falta de especialización, conocimientos y técnicas específicas, en la labor de programación y obligó a una profesionalización de la figura del/de la programador/a, que adoptó una fuerte influencia de EEUU. La evolución queda reflejada en dos definiciones de entidades públicas, la primera de la televisión pública española antes de la desregulación y la segunda publicada por el Consejo Superior del Audiovisual francés.

El profesional con formación a nivel universitario superior que es responsable individual, o corporativamente, de la estructura de la programación, de la búsqueda y selección de ideas, de la creación de contenidos, del control del proceso de elaboración de los mismos y de su expresión televisual, así como de la confección de los esquemas de programas, de la dirección de la emisión y del análisis y evaluación de los resultados. (Ordenanza Laboral de RTVE, 1977)

El programador participa en la definición de la línea editorial de la cadena, supervisa la selección de compras, orienta las inversiones de producción, planifica éstas en el tiempo y puede intervenir en su desarrollo. Sobretodo es un estratega y un táctico en el ordenamiento diario de los programas: elabora la parrilla. Dicho de otra manera, el programador tiene el riesgo cultural de la empresa televisiva. (Monique Dagnaud, Conseil Supérieur de l'Audiovisuel, 1990)

Hoy entendemos la figura del programador como el profesional que debe combinar dos facetas interdependientes. Por un lado, asume las labores de selección, 
coordinación y orientación de programas de diferente duración en una estructura determinada, que da como resultado la configuración de la parrilla. Por otro lado, realiza una eficiente búsqueda de correlato entre la oferta de programas y la audiencia del medio (real y potencial). Para ello, es fundamental que conozca en profundidad esta audiencia, tanto desde una dimensión cuantitativa como cualitativa. El programador debe, por tanto, tener conocimientos en el manejo de análisis cuantitativos (estimaciones de audiencia y prospecciones de resultados), cualitativos (estudios demográficos, del tiempo libre, culturales, etc.) y nociones de economía (para evaluar el coste de rentabilidad de los programas). Contreras y Palacio (2001) establecen el perfil del programador. Entre las funciones y obligaciones de la figura del/de la programador/a están:

1) Definir los marcos que establezca una audiencia en un medio determinado para un mercado dado (fijar el target al que hay que dirigirse).

2) Evaluar el potencial comercial de los programas y servicios disponibles en cada momento.

3) Saber donde encontrar los programas necesarios para conformar la planificación diseñada. Esto puede hacerse, fundamentalmente, mediante dos vías:

- Ordenando la realización de producciones propias.

- Negociando la adquisición de producciones ajenas.

4) Hacer la rejilla, seleccionando el horario y orden más conveniente de la emisión de programas. Aquí es fundamental el conocimiento de la competencia y la definición de imagen y discurso propio.

5) Participar en la autopromoción.

6) Controlar la continuidad.

7) Evaluar los resultados de audiencia conseguidos.

8) Cumplir con la normativa legal.

Teniendo en cuenta estas funciones, el trabajo del/de la profesional de la programación se agrupa en tres grandes ámbitos:

1) La planificación: encargado/a de fijar la visión general de la emisora y las necesidades de producción o compra.

2) El marketing: encargado/a de definir el punto de vista de los anunciantes y los aspectos comerciales.

3) La confección de la rejilla: encargado/a de articular la oferta y de estudiar sus resultados.

\subsection{Historia de la programación}

Para llegar a la definición actual de programación, es necesario revisar diferentes etapas evolutivas, que se encuentran conectadas a la propia evolución de los medios de comunicación. Así, las primeras necesidades programáticas surgen vinculadas a la radio, como un requisito para vender aparatos receptores radiofónicos. A partir de las pautas marcadas para la radio, la televisión forjaría su propia programación. 


\subsubsection{Origen de la programación radiofónica}

La programación surge en EEUU como necesidad para vender los aparatos receptores fabricados por RCA-General Electric, ATT y Westinghouse. La compañía General Electric era la empresa manufacturera de electrodomésticos más importante del mundo, y formó la Radio Corporation of America (RCA), tras absorber la American Marconi. David Sarnoff, empleado de la American Marconi, fue nombrado manager general de la RCA. Sarnoff había propuesto un proyecto que permitía transmitir a distancia sonidos, es decir, ofreció la primera definición del modelo radiofónico que conocemos y seguimos utilizando hoy en día. En 1916, Sarnoff propuso su modelo de radio como medio de comunicación centralizado y unidireccional, que tenía su rentabilidad económica en el consumo familiar y doméstico, a imagen del fonógrafo y la fotografía. Su propuesta no tuvo acogida, pero, a pesar de ello, elaboró un plan financiero que establecía un periodo de tres años para vender alrededor de un millón de aparatos de radio. El precio por aparato lo estableció en 75 dólares, lo que se traduciría en 75 millones de dólares para $R C A$. Por otra parte, Thomas Cowan, empleado de Westinghouse, recibió la orden, en 1921, de conseguir que la tecnología «hablase». Para ello tomó prestado un fonógrafo a Edison y elaboró la primera parrilla de programación con un horario estable y comenzó a emitir el 30 de septiembre de ese año, de 20:00h a 22:30h, con una programación basada en música, lecturas, seriales e información meteorológica y deportiva.

En el período de 1922 a 1924 la $R C A$ facturó ventas por valor superior a 80 millones de dólares y en todos los países, a excepción de la Rusia soviética, se iniciaron servicios radiofónicos con iniciativas privadas. Concretamente fueron los fabricantes y/o vendedores de aparatos de radio los encargados de elaborar contenidos como argumento de venta de los receptores. La programación de los años veinte tuvo como objetivo principal el económico, para vender receptores a particulares y crear un mercado radiofónico. En España, la pionera fue Radio Ibérica.

Al finalizar la Primera Guerra Mundial, Europa asistió a una oleada de intervención económica por parte del Estado sobre servicios e industrias. Esto marcaría el desarrollo posterior de la radio y, especialmente, de la televisión (Izquierdo-Castillo, 2014). La monopolización estatal de la radio está asociada a la figura de John Reith, primer director de la $\mathrm{BBC}$, que apostó por una programación horizontal. Esto aportó serialidad a la difusión, lo que contribuyó a la fidelización del público y a la estandarización de los procesos de producción. Las directrices de Lord Reith marcarían un concepto de radio y, posteriormente, de televisión, como un medio de esencia educativa y de elevación moral y espiritual, al margen del entretenimiento. Es el nacimiento de la triple función de servicio público de radiodifusión: informar, educar y entretener.

Por otra parte, la emisora privada francesa Radio Cité fue la primera en Europa en establecer una programación basada en la segmentación del público, en la década de 1930. A partir de los de estudios de audiencia rudimentarios, pudo establecer criterios de programación basados en indicadores como sexo y edad de la audiencia, así como la creación de programas específicos para colectivos concretos (audiencia femenina, audiencia infantil, audiencia de cabezas de familia, etc.). 


\subsubsection{Origen de la programación televisiva}

Las primeras emisiones regulares de televisión aparecen en la década de 1930 y el medio se consolida durante la década posterior. La televisión toma como espejo la radio para iniciar sus emisiones de contenido. Buena parte de las técnicas son heredadas, pero la televisión pronto mostraría un mayor potencial para la difusión mediática, lo que obligaría a adaptar y reformular las técnicas de programación.

Existen dos escenarios radicalmente opuestos en el origen de la televisión como medio: EeUU y Europa. El modelo de EEUU se caracteriza por tener a los anunciantes como principales programadores mientras que en Europa será el Estado quien asuma esa función. Dentro de Europa, destacamos el caso español.

\section{El caso de EEUU:}

En el periodo de 1930 a 1950, las televisiones vendían sus programas íntegramente a los anunciantes, que eran los encargados de realizar la programación. El resultado eran rejillas con pocos anuncios y compuestas por una gran mayoría de programas patrocinados. El patrocinio incidía directamente sobre los contenidos y la producción de los programas.

Este sistema fundamentado en la emisión de programas patrocinados fue eficaz para forjar el inicio de la televisión, pero a partir de la década de 1950 aparecieron los primeros desgastes del modelo. Los espacios televisivos eran mucho más caros que los radiofónicos, y resultaba cada vez más difícil que los asumiera un solo patrocinador. Se intentó que los programas fueran producidos por varios patrocinadores, pero perdían el protagonismo y dificultaban la asociación del espacio con el producto. Además, los dueños de las cadenas comenzaron a percatarse de que la televisión estaba llamada a ser la mayor industria del entretenimiento, como relevo del cine, y, por tanto, comenzaron a interesarse más por el control de su propio negocio. Esta corriente de cambio coincidió con un factor que, si bien resulta anecdótico, sirve para marcar el punto y aparte de la evolución televisiva y refleja el desgaste del modelo de patrocinadores. En 1956 se destapó el escándalo del programa concurso Twenty One, que había sido amañado para forzar la expulsión de uno de sus concursantes en favor de otro más atractivo para el patrocinador y la cadena.

A partir de ese momento, las cadenas asumirían el control de su programación y comenzaría a forjarse la figura del programador en un sentido moderno. Es el inicio de las técnicas complejas de programación, al servicio de la estrategia de la cadena. Los efectos del cambio de paradigma se apreciaron en la parrilla. Disminuyó el número de programas y aumentó su duración. Los índices de audiencia adquirieron un gran protagonismo y se incrementó la importancia de las series de ficción, por delante de los programas de plató. Todo ello comportó una reducción de la diversidad en la programación pero fomentó la aparición de una gran industria de exportación de ficción, que contribuiría a una homogeneización global de los contenidos. 
En Europa, se paralizaron los servicios televisivos a partir de la Segunda Guerra Mundial. En 1948 las únicas emisiones regulares de televisión que permanecían fueron las de Gran Bretaña, junto con las de EEUU. Sin embargo, en pocos años la televisión se generalizó en Europa y el resto de América. Fue gracias al doble modelo programático público-privado, que provenía del sistema radiofónico de preguerra, que se impuso en todos los países del mundo. Durante décadas, el sistema televisivo hegemónico en Europa fue de iniciativa pública casi absoluta y los monopolios televisivos constituyeron en su origen una garantía para establecer la base de reconstrucción ideológica y política de los países devastados por la guerra. En este contexto, existen, no obstante, diferencias en función de los regímenes políticos diversos en la Europa del momento. Así, no se formó la televisión de igual forma en el sistema democrático de Francia como en el régimen dictatorial de España.

El caso de España:

En España, la televisión apareció con bastante retraso. Fue en 1956 cuando comenzaron las primeras emisiones desde el Paseo de la Habana de Madrid. La televisión se introdujo como instrumento al servicio del régimen e ideología franquista y la programación siguió un esquema anárquico y no profesionalizado. No obstante, se intentó mantener un equilibrio entre las tres funciones de servicio público (informar, educar y entretener) y se intentó que cada persona encontrara al menos un programa de su interés, lo que demuestra una preocupación por atraer al público.

En 1981 se publicó el Estatuto de RTVE, que constituiría el primer documento escrito que coordinaba y armonizaba la programación en España. Este documento recoge los principios básicos de servicio público aplicados a la programación, basados principalmente en la rentabilidad social. Se trata de un documento similar al de otras cadenas europeas. Este documento fijaba 6 grandes principios para guiar la programación de la cadena pública:

a) Identificación con valores constitucionales.

b) Fortalecer sentimientos de unidad nacional, respetando la pluralidad.

c) Estimular diálogo y tolerancia.

d) Reforzar la legitimidad de las instituciones del Estado.

e) Explicar con rigor los problemas de la economía nacional.

f) Ser espejo de la realidad española.

Y dividía la programación en seis grandes áreas:

- Información y opinión.

- Cultura.

- Deportes.

- Entretenimiento.

- Infantil y juvenil.

- Educación y religión. 
La década de 1980 supuso la consolidación de una entidad pública centrada en contenidos de servicio público, en ocasiones arriesgados, tanto a nivel estético como crítico. Destacan los programas musicales (Popgrama, Último grito), infantiles (La bola de Cristal) y culturales (Metrópolis). En esta época también se inició un proceso de reducción del elitismo asociado a la segunda cadena de RTVE.

En esta misma década se produjo también la aparición de las televisiones autonómicas, que reproducían el modelo de programación de RTVE. La programación de estas cadenas destacaban por la importancia de la normalización lingüística y la incidencia en la creación de identidades propias. En su origen, las cadenas autonómicas emitían una franja reducida y apostaban por el entretenimiento, la información y los programas infantiles.

\subsubsection{El impacto de la desregulación}

La desregulación de la década de 1990 comportó una transformación en la programación televisiva. En Europa, la aparición de la televisión privada produjo un cambio de modelo, orientado a partir de ahora hacia la economía y que, en países como España, afectó al modelo de servicio público de radiotelevisión. Al mismo tiempo, en EEUU, donde la televisión siempre tuvo un carácter económico, privado y comercial, se produjo un cambio significativo con la aparición de la televisión de pago y la fragmentación de la oferta.

A partir de este momento, los factores económicos se apoderarían de la programación, lo que comportó la aparición del fenómeno de la telebasura y la fusión de los modelos públicos y privados. La investigación de las audiencias se convertiría en prioridad y se activó un mercado internacional de programas que contribuiría a la estandarización y homogeneización de contendidos. 


\section{Bloque 2}

Modelos, procesos

y técnicas de programación

\subsection{Modelos de programación}

Podemos diferenciar modelos de programación, en función de los modelos mediáticos. Realizamos una distinción por oposición en función de tres ejes:

- Público - Privado.

- Generalista - Temático.

- Gratuito - Pago.

\subsubsection{Modelo público de programación}

Las características básicas de este modelo son:

- Predominio de la planificación cultural en el diseño de las parrillas.

- Establecimiento de una dieta equilibrada entre los diferentes géneros y contenidos.

- Búsqueda de técnicas de programación basadas en la rentabilidad social del medio.

- Consideración de las minorías como público televisivo.

\subsubsection{Modelo privado de programación}

Las características básicas de este modelo son:

- Planificación estratégica destinada a la maximización de beneficios económicos.

- Predominio de los programas vinculados al entretenimiento y al ocio.

- Utilización de técnicas de programación altamente complejas para maximizar la audiencia y aumentar la eficacia mercantil.

- Programación orientada al gran público. 


\subsubsection{Modelo generalista de programación}

Las características básicas de este modelo son:

- Oferta caracterizada por la diversidad de géneros.

- El diseño de la programación se ve condicionado por el enfoque comercial.

- La programación se orienta hacia la búsqueda de audiencias masivas.

- Modelo unidireccional con carácter monológico.

- La programación se entiende como un flujo continuo.

- Fuerte peso del prime time.

- Vinculación con la gratuidad.

- Altos costes de producción.

- Importancia de la imagen de marca.

\subsubsection{Modelo temático de programación}

Las características básicas de este modelo son:

- Oferta constituida a partir de monogéneros.

- Vinculación con la televisión multicanal.

- Segmentación del público.

- Importancia de las guías de programación (EPG).

- Implantación de nuevas formas de emisión.

- Instauración de un discurso fragmentado.

\subsubsection{Modelo gratuito de programación}

Las características básicas de este modelo son:

- Asociado al modelo generalista.

- Acceso no condicionado a los contenidos.

- Financiación indirecta: impuestos y/o canon para modelo público y consumo publicitario para modelo privado.

\subsubsection{Modelo de pago de programación}

Las características básicas de este modelo son:

- Existe un acceso condicional, con especial relevancia de los abonos, que constata la existencia de públicos minoritarios dispuestos a pagar para ver la televisión a cambio de ventajas.

- Las principales ventajas son la disminución de la publicidad y el contenido Premium (fundamentalmente cine, fútbol y contenido infantil). 
- Es efecto de una crisis y agotamiento del modelo generalista.

- Plantea la necesidad de especialización.

- Está relacionado con las cadenas de multigénero y las temáticas.

- Las funciones básicas del/de la programador/a se dirigen hacia la captación y mantenimiento de abonados. Para ello es importante la configuración de un paquete equilibrado que pueda atraer a todos los miembros de una familia.

- El escenario multicanal donde se ubica la televisión de pago provoca un contexto donde coexisten múltiples parrillas, lo que provoca un cambio de concepto de programación, y aparecen nuevas técnicas de programación, como la redifusión.

- Importancia de la autopromoción.

\subsection{El proceso de construcción de la parrilla de programación}

En el proceso de construcción de la parrilla de programación, una cadena o emisora debe considerar el escenario de competición en el que va a ubicarse. Los principales escenarios son:

- Confrontación directa:

- Enfrentamiento abierto en todos los targets.

- Oferta similar entre cadenas.

- Éxito o fracaso (equidad poco frecuente).

- Coexistencia complementaria:

- Coexistencia de espacios.

- Búsqueda de huecos de subsistencia.

- Conocimiento del mercado.

- Búsqueda de alternativas:

- Públicos minoritarios no atendidos.

- Crecimiento de canales.

- Dificultad: métodos de financiación para la rentabilidad.

Una vez elegido el contexto de competición, se procede a la elaboración de la parrilla. Para ello, Contreras y Palacio (2001) proponen «el juego de las órbitas», un modelo de construcción de parrilla basado en dos fases claramente diferenciadas. Se trata del diseño de dos órbitas, que denominan de Planificación y de Aplicación, y que se rigen ambas por dos principios clave: el Principio de la Sucesión y el Principio de la Inagotabilidad.

En primer lugar se diseña la Órbita de Planificación. La órbita de la Planificación se compone de ocho fases:

1. Posición en el mercado:

- Ver el reparto inicial de audiencia y de publicidad.

- Valorar cuantitativa y cualitativamente el tipo de cadena y el tipo de público. 
2. Aspiraciones: definición del concepto base de futuro de la cadena.

- Liderazgo.

- Replanteamiento espíritu compañía.

3. Expectativas de audiencia: razonable sobre el share y la cuota de mercado publicitario.

4. Público: conocer las cifras pero también la tipología de público que se quiere conectar con el proyecto.

5. Producto disponible: balance de existencias.

- Contratos firmados pendientes de cumplir.

- Material de archivo a la espera de emisión.

- Productos adquiridos con objetivos diferentes a los de ese momento.

6. Producto buscado: en función de lo que se necesita.

7. Dinero que se necesita: para pagar lo que se ha encontrado.

8. Dinero disponible: conocida la cifra de gastos hay que cotejarla con la de ingresos y las posibilidades de inversión de los socios del negocio. Si la cifra es negativa habría que volver al primer punto y bajar las expectativas para volver a ajustar el proceso.

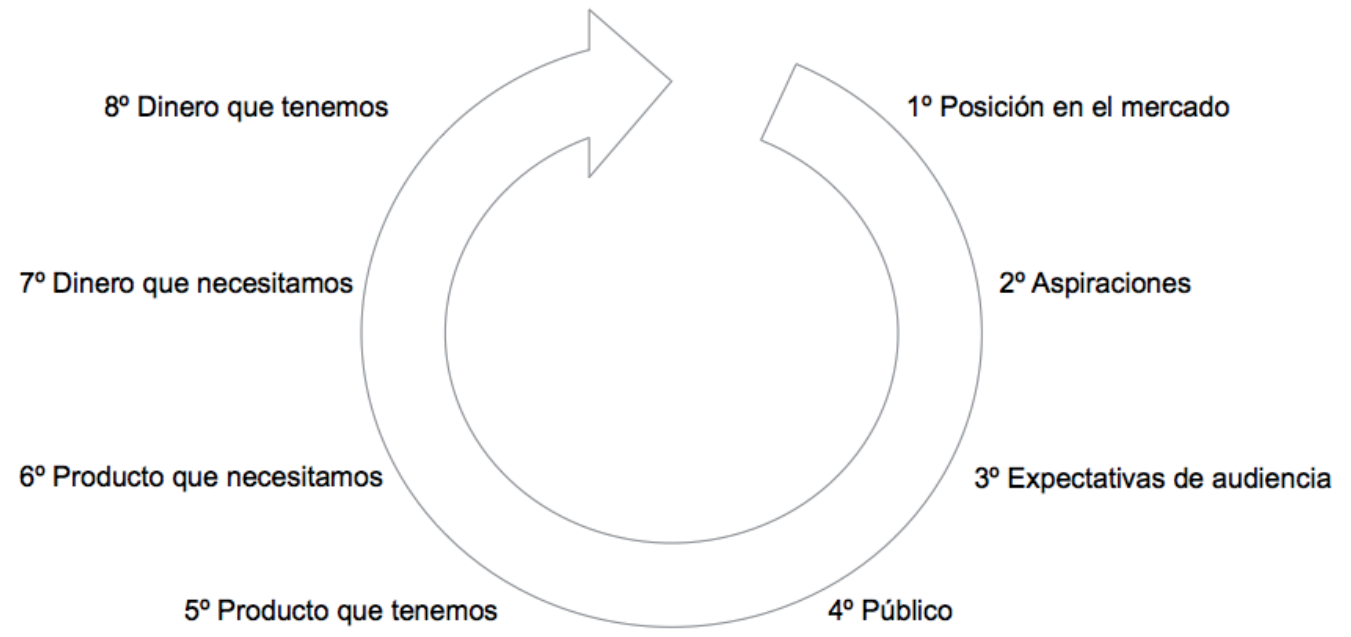

Fuente: Fuente: Contreras y Palacio, 2001: 159

Una vez realizada la planificación, se ejecuta la Órbita de la Aplicación:

1. Competidores: análisis de los competidores directos del mismo mercado (cuantitativo y cualitativo).

2. Imagen de cadena: valoración de la personalidad, análisis de los rasgos estéticos generales del target y del contenido. 
3. Previsión de evolución: a medio plazo, evitando rupturas que rompan con la imagen que es difícil de crear.

4. Diseño de la programación: con solidez y continuidad.

5. Almacén de programas: material preparado para emitir en cualquier momento.

6. Fabricación de productos: con planificación.

7. Distribución de la rejilla: con el esquema y las piezas enlatadas y ad hoc se completa la rejilla.

8. Rendimiento de antena: análisis de los programas (retoques). Si es negativo habría que comenzar en el primer paso.

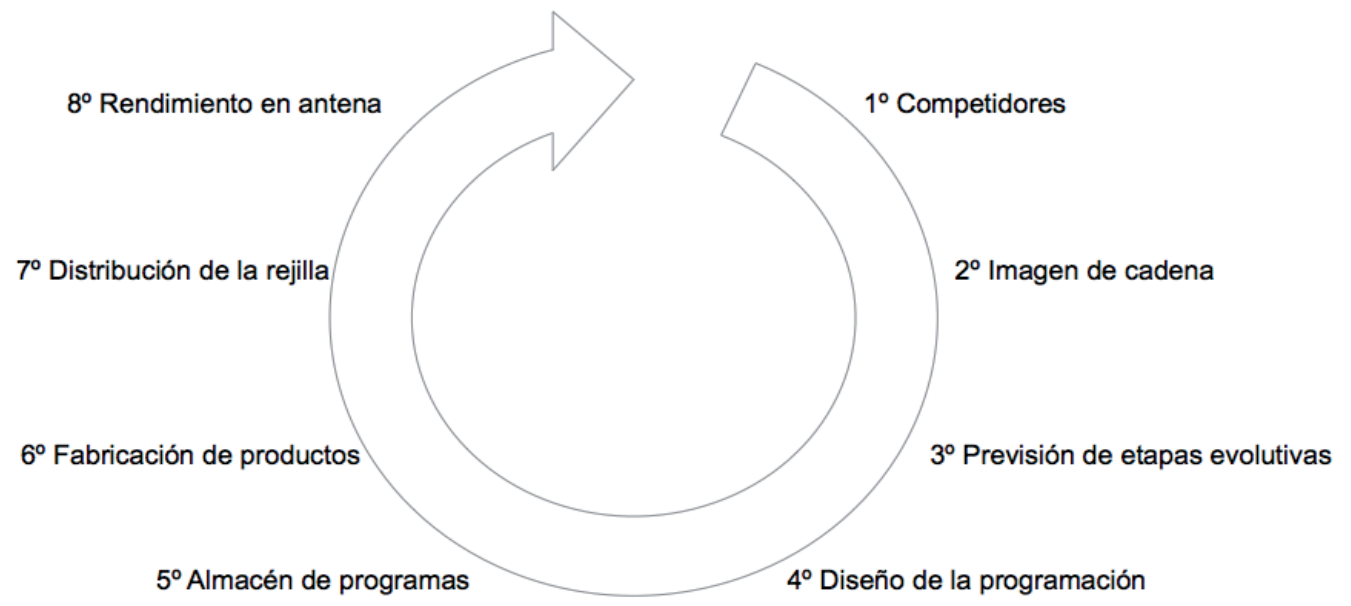

Fuente: Contreras y Palacio, 2001: 161

\subsection{Las estrategias y técnicas de programación}

Para la construcción de la parrilla, se siguen los siguientes pasos:

1. ${ }^{\circ}$ Consolidación de los cimientos. Los cimientos de la programación varían en función del tipo de cadena. Así, en las cadenas generalistas, los cimientos suelen formarse con los programas informativos, al inicio de cada bloque (matinal, vespertino, nocturno). Por su parte, en las cadenas de pago, puede ser un estreno cinematográfico diario, como ocurría con la primera cadena española de pago, Canal Plus.

$2 .^{\circ}$ Edificación de la parrilla. Se organiza por bloques y mantiene una organización horizontal y vertical.

3. ${ }^{\circ}$ Ubicación de los programas. Dentro de cada bloque se disponen los diferentes programas. 
La parrilla se construye considerando una doble dirección: vertical y horizontal. Las técnicas verticales permiten crear un hilo conductor entre los programas, que facilita el tránsito de audiencia. Por su parte, las técnicas horizontales permiten la memorización en la audiencia, que genera unos hábitos de consumo mediático y posibilitan la fidelización.

Podemos diferenciar tres tipos de estrategias generales: de localización, de formato y de caracteres.

1. Estrategias de Localización. Se trata de aquellas que tienen que ver con la ubicación de los programas en la parrilla. Algunas de las técnicas son:

a) Stunting (golpes de efecto): consiste en realizar un movimiento o cambio de espacios, con la intención de desestabilizar a la competencia. En su aplicación más agresiva puede incurrir en una falta grave (contraprogramación).

b) Blocking (en bloque): consiste en aunar productos de características o target similares con el objetivo de crear un flujo de audiencia homogéneo en un bloque de programas, siguiendo una orientación vertical.

c) Lead-in (punta de lanza): estrategia relacionada con los programas de acceso (los que preceden a otros importantes normalmente en prime time). El objetivo es atraer audiencia para que permanezca durante el programa que les sigue.

d) Hammock (hamaca): consiste en colocar un producto nuevo o débil entre dos de programas con audiencia. El objetivo es aprovechar el arrastre de audiencia del primer programa y la expectativa del tercero.

e) Tent poling (tienda de campaña): variación de la hammock con el orden invertido. Se trata de colocar un programa de éxito entre otros dos que no obtienen tanta audiencia o que son nuevos.

f) Bridging: consiste en comenzar el programa unos minutos antes que el del competidor, con el objetivo de captar la atención de los espectadores y mantenerlos cuando la competencia comience su programa. Suele utilizarse en los cimientos (informativos) o comienzos de bloque.

g) Stripping (en tira): consiste en programar un mismo programa a la misma hora cada día de la semana. Se busca la fidelización del público (programación en horizontal). Esta técnica permite crear un concepto fácil de memorizar para los públicos, con lo que se consigue fidelizar audiencia. Además, permite estabilizar los resultados de audiencia de la cadena. No suele emplearse para prime time, ya que es caro y el espectador busca más variedad en esa franja.

h) Programas de bajo coste: suele producirse en verano ya que desciende el número de espectadores. Consiste en programar rerums (segundos o terceros pases de series) o formatos de bajo presupuesto.

2. Estrategias de Formato. Se trata de acciones que tienen que ver con los contenidos o con el formato de los programas televisivos. 
a) Programa Especial: se trata de un programa único, normalmente consistente en la retransmisión de un evento (frecuentemente de coste alto). El objetivo es reforzar la imagen del canal y obtener más audiencia de la habitual.

b) Blockbuster: consiste en aplicar el tratamiento de programa especial a una película.

c) Long form: son programas de larga duración que suelen abarcar la totalidad de un bloque, normalmente de tarde o de noche. Ejemplos: maratones, películas de larga duración, miniseries, etc.

d) Loss leader: se trata de programas que no persiguen necesariamente aumentar la audiencia, ya que su emisión se basa en la validez del tema y el momento de emisión. Por ejemplo, especiales informativos sobre una acontecimiento no programado.

e) Clipping: esta técnica consiste en buscar la sinergia entre bloque y bloque o entre programa y programa. Un ejemplo habitual consiste en cortar los títulos de crédito para ganar tiempo y evitar la fuga de audiencia.

3. Estrategias de Caracteres. Afecta a los conductores de programas, protagonistas de series o la trama de guión.

a) Crossover: se basa en el traslado puntual de personajes populares en una serie o programa a otro.

b) Spinoff: consiste en la creación de una serie o programa a partir de otro y toma como base un personaje secundario o principal con peso específico.

c) El cebo: se basa en la promoción de acciones previas al programa que buscan atraer a la audiencia como gancho que genera expectativa. Por ejemplo, participar en un concurso.

d) Golpe bajo: se trata de un programa que parodia al programa de la competencia.

e) Cambio de canal: consiste en arrebatar a una cadena sus presentadores más demandados, con el objetivo de atraer al target y público que asociado a este/a presentador/a. 


\section{Bloque 3}

Los públicos y la investigación de audiencias

\subsection{La investigación de audiencias}

La investigación de audiencias es una vía de conocimiento del comportamiento de la sociedad respecto del medio televisivo. Permite conocer el tamaño y la composición sociodemográfica de la audiencia y sus resultados no solo sirven a los medios de comunicación, sino que adquieren relevancia social y económica.

La investigación de audiencia, cualitativa y cuantitativa, ha tenido un importante desarrollo y ha utilizado diversos métodos y técnicas, a través de organismos y entidades encargadas de los trabajos.

La investigación tradicional se centra en cinco campos (Bigné, 1981: 728-764):

1. Número y perfil sociodemográfico.

2. Opinión que les merecen los medios y sus soportes.

3. Niveles de duplicación en el consumo de medios: cuántos, cómo y dónde se producen las reiteraciones en el contacto con los medios y sus contenidos.

4. Concomitancias entre programación y los mensajes publicitarios insertados.

5. Relación entre los estilos de vida y los hábitos de consumo de medios.

En la investigación centrada en la televisión (Fergusson, D., Meyer, T. e Eastman, S.: 2009: 42-44) destaca el contenido de los programas y la relación entre los componentes de un programa y la audiencia. Esta investigación puede hacer en tres momentos:

- fase del diseño-concept testing

- programa piloto-test al programa piloto

- durante la emisión-program testing

La investigación de audiencias puede ser cuantitativa o cualitativa.

Investigación cuantitativa:

- Método:

- Encuesta personal aleatoria

- Panel de audiencia

- Amplitud:

- Monomedia 
- Multimedia

- Media-producto-marca

- Ámbito geopolítico: European Social Survey, Europanel, PETAR (Nielsen Europe), Pan-European Media and Marketing Survey (Synovate), Eurodata TV (Médiamétrie).

Momento en el que se realizan:

- A posteriori

- Coincidentales

- Prospectivas

- Ámbito sociodemográfico

La investigación cualitativa:

- Entrevista

- Grupo de discusión o Focus Group o Dinámica de grupo

- Delphi: consenso obtenido por expertos, con carácter prospectivo

- Observación

\subsection{Los índices de audiencia}

Podemos definir audiencia como el conjunto de personas que han estado en contacto con un medio de comunicación durante un periodo de tiempo determinado. A partir de aquí, podemos diferenciar múltiples índices:

- Audiencia potencial: número máximo de personas que pueden contactar con un medio (población o universo sometido a estudio).

- Audiencia objetivo: parte de la audiencia potencial a la que se dirige un programa o mensaje publicitario determinado.

- Audiencia útil: parte de la audiencia que cumple los elementos definitorios del público objetivo.

- Audiencia bruta: cantidad absoluta de personas que han visto u oído un programa, contabilizándolas todas y cada una de las veces que han contactado con el medio.

- Audiencia neta: total de personas distintas que forman parte de la audiencia de un medio o programa, en un tiempo determinado; se obtiene eliminando las duplicaciones de audiencia bruta para que cada persona se cuente solo una vez.

- Rating: indica la media de consumo de un medio o programa en relación a la audiencia objetivo o target. Tiene en cuenta la audiencia bruta (duplicaciones). En televisión la unidad mínima de tiempo es cada minuto. En radio es cada cuarto de hora. 
- Audiencia acumulada o Reach: audiencia neta de un medio o programa en relación a la audiencia objetivo o target, que tuvieron contacto con el medio o programa al menos un minuto. No se tienen en cuenta las duplicaciones.

- Audiencia máxima y mínima: la máxima es un parámetro que ilustra el momento en el que se ha producido el número más alto de individuos siguiendo un programa o canal, la mínima da la referencia del instante en el que se contabiliza un número menor.

- Audiencia total (TTV): total de personas que están viendo la televisión en un período de tiempo determinado (un programa, una franja horaria, etc.). El total televisión se utiliza como base para calcular la cuota de pantalla de cada canal.

- Índice de aportación de la cadena: mide la relación entre la audiencia de un programa determinado con respeto a la audiencia global del canal, para un período de tiempo determinado.

- Cuota de pantalla o Share: mide la distribución de la audiencia entre canales. Toma como referencia la audiencia media del total de personas (TTV) en un periodo de tiempo determinado y qué parte de esa audiencia corresponde a cada canal. Se utiliza para indicar el éxito de un programa sobre la competencia.

\subsection{La audiencia y la publicidad}

Los índices relacionados con la audiencia mediática se transforman en índices útiles para la publicidad:

- Impactos: cada vez que una persona ha sido expuesta a un mensaje publicitario. Se mide en miles de individuos y equivale a la audiencia bruta.

- Frecuencia: número de veces que una persona ha estado expuesta a un anuncio; indica el promedio de impactos por individuo, pero también puede servir para conocer el porcentaje de personas que han sido impactadas dos veces, tres veces, etc.

- Cobertura: total de personas que han sido impactadas, por lo menos una vez. Equivale a la audiencia acumulada (reach). Se puede expresar en términos absolutos (miles) o en porcentajes en relación al público objetivo. Sirve para indicar la eficacia de una campaña publicitaria para llegar, por lo menos una vez, a un número determinado de personas.

- Gross Rating Point (GRP): Número de contactos, en porcentaje, sobre un target determinado. 
- Coste Por Mil (CPM): coste que supone alcanzar mil contactos en un soporte o en una campaña formada por varios soportes.

- Coste Por Contacto (CPC): coste que supone alcanzar un contacto en un soporte o en una campaña formada por varios soportes.

- Oportunity To See (ots): número medio de veces en que los individuos contactados del target tendrán la oportunidad de ver el anuncio. Se calcula como GRP's / Cobertura.

\subsection{La audimetría}

La televisión mide la audiencia principalmente a partir de la técnica de audimetría. Se trata de una herramienta de investigación de mercados aceptada por todos los agentes implicados y aprobada en más de ochenta países. Se basa en una metodología consensuada y con controles de calidad, tanto internos como externos.

La audimetría se compone de un panel de audímetros, que son aparatos que miden el consumo televisivo. Los resultados, en España, se comparan con el Estudio General de Medios (EGM), que se basa en entrevistas y visitas.

En los años veinte, con la radio como medio en consolidación, se producían sondeos de audiencia, a partir de entrevistas telefónicas, principalmente, motivadas por la presión de los anunciantes. Estos sondeos podían realizarse hasta cuatro veces al día, con preguntas como: ¿Qué emisora tenía sintonizada hace 3-6 horas?

Estos sondeos se basaban principalmente en:

- Entrevista basada en el recuerdo.

- Entrevistas personales + lista-recuerdo.

- Diarios de escucha (países con pocos recursos).

A partir de la década de 1930 se introdujeron nuevas técnicas, como la audimetría, que más tarde dejaría de ser útil para la radio, debido a la gran penetración del medio y a factores vinculados a su movilidad (transistor). La audimetría se retomó dos décadas después para la medición de audiencias televisivas.

Etapas en la evolución de la audimetría:

$1^{a}$ Generación de audímetros

Dispositivo electrónico (papel):

- Radio (1934).

- Arthur C. Nielsen (fundador ACNielsen) publicó en 1942 los primeros índices de audiencia (800 hogares).

- El desarrollo de la radio lo hizo ineficaz. 
En la década de 1950 se implantaron los audímetros para la medición de la audiencia televisiva. Eran audímetros pasivos, que combinaban los resultados con los diarios, sobre todo en Europa, donde esta combinación perduró hasta la década de 1980, con un sistema televisivo de pocos canales y un mapa de televisores reducido a un receptor por hogar. Los audímetros, de la compañía ACNielsen, registraban los datos en una cinta magnética y recopilaban información del número de usuarios (no identificados), el canal y el tiempo de consumo.

\section{$3^{a}$ Generación de audímetros}

En la década de 1980 se implantan los audímetros activos. Permiten la identificación a través del mando y proporcionan datos individualizados de consumo. Ya no registran en cinta magnética, sino que se basan en memorias electrónicas y transmiten la información mediante la línea telefónica. En Europa llegaron en 1984, al Reino Unido e Italia. En España, RTVE adjudicó a la empresa Ecotel (absorbida más tarde por Sofres) la investigación de audiencias en 1986, pero no reconoció la audimetría hasta 1988.

\section{$4^{a}$ Generación de audímetros}

La siguiente generación de audímetros se caracteriza por una introducción de mejoras, como:

- Capacidad de memoria.

- Velocidad de transmisión.

- Autonomía (en caso de carencia fluido eléctrico).

- Más control sobre los equipos asociados.

- Reducción de tamaño.

\section{$5^{a}$ Generación de audimetros:}

La última generación de audímetros continúa con la introducción de aplicaciones que permitan adaptarse a la complejidad del sistema audiovisual:

- Adaptados a la gran variedad y cantidad de medios.

- Que registren las situaciones reales sin ningún tipo de error.

También destaca la propuesta de prototipos que intenta monitorizar la atención de la audiencia y adaptarse al consumo en movilidad. Se trata de prototipos de audímetros personales, pasivos y multimedia. El principal problema de estos dispositivos es la invasión de la intimidad personal.

En España, destaca el Estudio General de Medios (EGM) para la medición de audiencias, tanto radiofónicas como televisivas. El EGM se basa en la realización de encuestas personales y telefónicas. 
Para la televisión, el EGM sirve de contrapunto a la medición principal, basada en la audimetría, a cargo de la empresa Kantar Media.

\subsection{Ventajas y limitaciones de la audimetría}

Las principales ventajas de la audimetría son:

- Precisión: segundo a segundo.

- Fidelidad: al utilizar un panel o muestra fija es posible la observación y estudio de los comportamientos individuales durante periodos de tiempo largos.

- Objetividad: no hay error de la información basada en recuerdo (diarios); la información la suministra el audímetro.

- Inmediatez: los datos se procesan y envían en poco tiempo.

- Información: gran cantidad.

Las principales limitaciones de esta técnica de medición son:

- Duda sobre la autoría del registro memorizado.

- Manipulación incorrecta del mando.

- Olvidos de identificación antes/después del programa.

- Cambio de actitud (presión).

- Recoge las acciones, no las opiniones.

- No valora la atención.

- No recoge la audiencia de los lugares públicos. 


\section{Bloque 4}

\section{Géneros y formatos de radio \\ y televisión \\ Tendencias en el mercado español}

\subsection{Definición de género}

El género es un sistema de presuposiciones compartidas entre emisor y receptor. La RAE lo define como «cada una de las distintas categorías o clases en que se pueden ordenar las obras según rasgos comunes de forma y de contenido».

La definición de género persigue un triple objetivo:

1. Facilitar la organización del trabajo profesional.

2. Procurar la nomenclatura que permita el estudio en profundidad.

3. Sistematizar la enseñanza de las distintas destrezas profesionales.

\subsubsection{Definiciones de género radiofónico}

Martínez-Costa y Díez (2005:97):

Modelos de representación de la realidad que otorgan estructura y orden a los contenidos de la radio para conseguir la creación de sentido por parte del emisor y la interpretación de sus mensajes por parte del receptor.

Alcudia (2008: 27):

Los géneros radiofónicos son categorías de programas que se fundamentan en un acuerdo implícito entre emisores y receptores, conforme a un conjunto de reglas de producción institucionalizadas y reconocibles. 


\subsubsection{Definiciones de género televisivo}

Wolf, M. (1984):

- Modos de comunicación culturalmente establecidos, reconocibles en el seno de determinadas comunidades sociales.

- Sistemas de reglas a las cuales se hace referencia (implícita o explícita) para realizar procesos comunicativos, ya sea desde el punto de vista de la producción o del de la recepción.

- El género se presenta como un racimo (clustering) de propiedades textuales e intertextuales.

- Se define por un complejo sistema de rasgos, de relaciones entre contenidos, formas, roles discursivos, actos lingüísticos, etc.

- El análisis del género exige que se definan los diversos códigos expresivos que aparecen en el texto (imagen en movimiento reproducida cinematográficamente, imagen fija, imagen en movimiento producida electrónicamente, música, ruidos, etc.) así como sus interrelaciones.

Ryan, M.L. (1988):

- Clubes que ponen un cierto número de condiciones para pertenecer a ellos, pero que toleran como semimiembros a las personas que satisfacen sólo algunos de los requisitos y que no parecen estar afiliados a ningún otro club. En el momento en que los semimiembros se hacen más numerosos, las condiciones de admisión pueden modificarse de tal modo que éstos lleguen a ser miembros de pleno derecho.

- «regularidades-ligadas-al-género»: conjunto de regularidades que, sin ser reglas constitutivas del género, se asocian igualmente a su funcionamiento comunicativo. Pueden ser: sistemas de expectativas, hábitos de recepción, importancia atribuida al programa, criterios de programación, etc.

\subsection{Géneros televisivos}

\subsubsection{Géneros de Información}

- Informativo:

- Más característico del género.

- Puntos clave de la franja programática.

- Política, economía, sociedad, etc.

- Información meteorológica y deportiva (pueden ser independientes).

- Editor: decide los acontecimientos que se cubren, los medios y la extensión. 
- Producción propia o compra de material (agencias o freelancers).

- Reparto de recursos:

+ Acontecimientos emergentes: triunfos deportivos, atentados, desastres naturales, incendios, etc.

+ Eventos rutinarios y/o anunciados: sesiones del Congreso, audiencias públicas, giras del presidente del gobierno, inauguraciones, ceremonias, ruedas de prensa, etc.

+ Soft News: campañas de vacunación, las rebajas, notas sobre vida cotidiana (los parques, la siesta, el ahorro, etc.).

- Edición especial:

- Esporádico y monográfico.

- Acontecimiento extraordinario (elecciones, visitas oficiales, etc.),

- Compendio de varios géneros de información periodísticos: entrevistas, reportajes, coloquios y ruedas informativas.

- Flash informativo:

- Noticia breve.

- Carácter «urgente».

- Acontecimiento inesperado.

- Gran repercusión social.

- Interrumpe la programación.

- Cuando están programados actúan como Avances Informativos.

- Opinión y/o debate:

- En algunos países ocupan posición central en la parrilla.

- Dirigidos por periodistas de reconocido prestigio.

- Periodicidad diversa: semanal, diario, etc.

- Suelen incluir: investigación periodística, invitados especiales o tribunas con público participante.

- Reportajes:

- Contribuye a una imagen de prestigio de la cadena.

- Despliegue de medios de producción humanos y técnicos.

- Periodicidad: semanal.

- Informe semanal.

- Canal 24 x 7:

- Vinculado a canales temáticos.

- Estructura de la «rueda» (30 minutos).

- BBC World, cnN, FoxNews Channel, Sky News, Bloomberg Television, Canal 24 horas, etc. 


\subsubsection{Géneros de Ficción}

- Miniserie:

- 2-3 episodios (4-6 horas).

- Una trama principal única que se resuelve al finalizar la serie; cada episodio suele finalizar con un clímax que genera expectación.

- Adaptaciones literarias.

- Historias de la vida real.

- Biografías de personajes célebres.

- Periodicidad: semanal o diario en continuidad.

- Tv Movie/Telefilm:

- 1,5-2 horas.

- Programación: sobremesa S-D.

- Diferencias con película cinematográfica.

+ Estéticamente:

- Pocos planos generales.

- Abuso del primer plano.

+ Técnicamente:

- Estructura de actos en función de cortes publicitarios.

+ Producción:

- Plazos breves.

- Número reducido de personajes.

- Decorados limitados.

- Tramas sencillas y directas.

- Serie:

- Modelo más específicamente televisivo.

- Consecución episódica de relatos.

- Número de personajes fijos.

- Tramas:

+ Continúan durante varios episodios.

+ Concluyen en cada episodio (episódicas).

+ Estructuradas en función de cortes publicitarios.

- Pocos decorados.

- Formatos:

+ Comedias de situación:

- Origen en Eeuu (década de 1950).

- Duración episodio treinta minutos (un intermedio).

- Para todos los públicos y para públicos segmentados.

- Contenidos:

Vida cotidiana de los personajes.

Realismo.

Búsqueda del elemento cómico (personajes estereotipados, contextos incoherentes, etc.). 
- Punto de vista formal:

Teatralidad.

Pocos personajes y decorados.

Interiores.

Risas enlatadas.

Presencia público.

Tramas episódicas autoconclusivas.

- Continuidad: relaciones entre personajes para fidelizar audiencia.

+ Telenovela:

- Origen latinoamericano.

- Estructura narrativa: trama principal (índole romántico) y secundarias.

- Trama principal: relación imposible por impedimentos contextuales (conflictos familiares, de clase, terceras personas, etc.) que hacen culebrear la trama.

- Final: triunfo del bien sobre el mal.

+ Soap Opera:

Origen comercial (EEUU-'50).

Tramas abiertas.

Originalmente dirigido a mujeres amas de casa.

Temas relacionados con los sentimientos y con las relaciones humanas (intriga, conflicto, traición, injusticia, amor, etc.).

Personajes estereotipados.

+ Drama:

- Temáticas y contenidos heterogéneos: acción, misterio, intriga, basadas en profesionales, etc.

- Suele tomar como base la realidad no cotidiana (verosimilitud).

- Elementos de continuidad en las tramas: relaciones entre personajes fijos, tramas generales (temporada).

- Tramas episódicas: comienzan y terminan en el episodio. Son las tramas principales, combinadas con las tramas de larga duración que actúan como telón de fondo.

+ Dramedia:

- Combina tramas propias del drama con elemento de la sitcom.

- Duración por episodio: 50-75 minutos.

- Una trama principal y dos o tres tramas secundarias.

- Trama general que recorre la serie a través de los episodios (continuidad y fidelización).

- Cubre largas franjas de programación, especialmente el prime time (España).

- Sin presencia de público.

- Decorados interiores y exteriores.

- Reparto coral. 


\subsubsection{Géneros de Entretenimiento}

Son contenidos basados en la sorpresa, el humor o el sentimiento. Existe una interrelación e identificación con el espectador.

- Magazines: compendio de géneros de todo tipo fruto de la lucha por concentrar las audiencias y atraer a los anunciantes. Combina información, opinión, entretenimiento y espectáculo.

- Combinación de varios géneros (información, concursos, actuaciones, realities).

- Cubren franjas amplias de programación.

- Carecen de una forma establecida: uno o varios presentadores, predominancia de la entrevista, etc.

- Galas y variedades:

- Grupo de presentadores de distinto sexo.

- Actuaciones variadas: musicales, ballets, desfiles, sainete.

- Estética luminosa, festiva, glamurosa.

- Gala:

- Programa especial y único.

- Reúne estrellas del momento del campo artístico tratado.

- Contenidos temáticos: programación de la cadena, homenaje a un artista, conmemoración de alguna región, entrega de premios (ТР, Goya, Oscar), benéficas (variante: maratones).

- Prime time.

- Concurso:

- Ingredientes: azar / méritos / (estrategia).

- Tipología:

+ De conocimientos/temáticos: preguntas-respuestas.

+ De habilidades/pruebas: superación de pruebas.

+ De actuaciones/artistas: cualidades creativas.

- Telerrealidad:

- Talk-show (Reality-magazine):

+ Muestran las tragedias, dramas o escándalos de personajes (anónimos o famosos) que desnudan sus secretos o emociones sin tapujos:

- Presentador/a entrevista a un grupo de personas presentes en el estudio sobre una parte de su vida privada.

- Tratamiento espectacular de la temática forzado hacia lo extravagante.

- Polémica.

- Reality-concurso:

+ Competición entre personas que ofrece una supuesta realidad en un contexto artificial.

+ Plató: debate con amigos y familiares de los concursantes.

+ Presentador de plató y presentador de enlace. 


\subsection{Géneros radiofónicos}

\subsubsection{Programas informativos}

Los programas informativos son el referente fundamental de la parrilla generalista radiofónica. Constituyen la seña de identidad y se basan en los géneros de noticias o informaciones (fórmula estrella), las crónicas y los reportajes.

- Boletín horario:

- Generalistas y musicales.

- Resumen cada hora en punto (3-5 min).

- Aportan continuidad programación.

- Informativo:

- 30-60 min.

- Combinación de diferentes voces (redactores, conexiones, grabaciones, entrevistas).

- Tipos y características.

+ Información de un minuto, aproximadamente.

+ Matinal: política, nacional/internacional, servicios (carretera/tiempo).

+ Mediodía: resumen actualidad del día (conexiones).

+ Nocturnos: tertulia (analizar/reflexionar/opinar) sobre actualidad diaria de carácter político, económico y cultural.

- Flash informativo:

- Adelanto de una noticia importante o inesperada que interrumpe la programación.

- Informativo especial:

- Hecho o noticia de gran relevancia que puede estar previsto (refleja la calidad técnica e informativa) o ser imprevisto (pone a prueba la profesionalidad del programa).

- Informativo especializado:

- De actualidad, monográfico.

- Periodicidad diaria o semanal.

- Formato Todo Noticias:

- Combina actualidad (prioridad), servicio público e interés social y cultural.

- Hot Clock: esquema horario de programación que se repite (20-30 min) y que genera hábitos de escucha y rutinas (expectativas).

- Europa: públicos / EEUU: privados. 


\subsubsection{Programas deportivos}

Los programas deportivos estaban incluidos en los espacios informativos, pero se independizaron. Tienen una gran relevancia mediática y social y constituyen un espectáculo radiofónico. Los formatos principales son: programas, carruseles y magacines.

- Programas deportivos:

- Información deportiva (noticias, crónicas, entrevistas, reportajes).

- Noticiario.

- Multiplex/multiconexión: con emisoras de la cadena.

- Jefes de deporte.

- De media a una hora.

- Fútbol.

- Última hora franja de la tarde.

- Carrusel:

- Directo de eventos deportivos.

- Multiconexión: rueda de conexiones que se suceden periódicamente a lo largo de un periodo de tiempo amplio (seis horas).

- Información y espectáculo (directo: simultaneidad, inmediatez, sensación de riesgo).

- Combina otros formatos radiofónicos: entrevistas (protagonistas directos a pie de escenario deportivo), reportajes, informaciones, conexiones con comentaristas, etc.

- Magazine deportivo:

- Emisoras privadas.

- Medianoche.

- Generalistas.

- Entrevistas con deportistas, directivos o ejecutivos de federaciones y entidades deportivas, autoridades del mundo del deporte y tertulias con colaboradores.

\subsubsection{Programas dramáticos}

- Constante desde su inicio.

- Ahora es residual: permanece como elemento en la publicidad y en algunos programas guionizados.

- Decadencia: finales de los sesenta.

- Subgéneros:

- Folletines o melodramas.

- Adaptaciones seriadas:

+ Historias del Oeste.

+ Aventuras de ciencia-ficción.

+ Series costumbristas.

+ Policíacos.

+ De humor. 


\subsubsection{Programas musicales}

La música forma parte de la radio desde su origen. Existen múltiples clasificaciones de géneros y formatos musicales.

- Pedrero (2000) propone la siguiente clasificación, tomada de clasificaciones de radio EEUU:

- Contemporary Hit Radio (CHR).

- Adult Contemporary (AC).

- Música étnica (Country, Hispano, Tejana).

- Gold (Oldies, Hits clásicos, Nostalgia).

- Beautiful Music.

- Urban.

- Alternative / Modern Rock.

- Classical.

- New Age Contemporary.

- Por su parte, Ortiz y Volpini (1995) proponen la siguiente:

- Programa dedicado a listas de éxitos o Top.

- Programas de música especializada.

- Programas revista musical.

- Programas musicales de autor.

- Miguel Ángel Nieto distingue los siguientes formatos:

- Música de éxito: listas más vendidas (EEUU - importado en '60).

- Novedades musicales: diferenciación en la forma de presentar los discos.

- Música de intérprete: siguen la carrera de un intérprete.

- Música de autor: obra de un compositor.

- Música del recuerdo: formatos diversos (décadas, países, intérpretes, autores, etc.).

- Música sinfónica: formatos (actualidad, divulgación cultural, transmisión, conciertos, etc.).

- Música nacional (regional, popular, folclórica, moderna, etc.).

- Historia de la música: evocan épocas concretas que pueden retrotraer a los oyentes hasta tiempos pasados.

- Música de compañía (acompañamiento).

- Música especializada (segmentada por públicos). 


\subsubsection{Programas de participación de la audiencia}

Estos programas constituyen un género con diferentes modalidades, estructura y fines definidos. Pueden operar con autonomía respecto a otros géneros y están plenamente consolidados en la radiodifusión de muchos países.

La radio es uno de los medios más interactivos (junto con Internet) y entre las razones de éxito se encuentran:

- Afán de la radio de servicio público y su carácter interactivo, plural y democrático.

- Su efecto de fidelización entre los oyentes.

- Periodísticamente, puede convertirse en una fuente de información valiosa.

- Desde el punto de vista empresarial: ahorro coste-eficacia.

Los programas pueden diferenciarse por la tipología de la participación:

- Participación esencial: no podrían hacerse sin la participación de los oyentes.

- Programas de consulta: origen en la posguerra y potenciado con la implantación y desarrollo del teléfono.

- Programas de petición: prolongado en el tiempo (30-80 min) y vigente hoy.

- Concursos: pérdida de importancia a favor de los televisivos.

- Programas de desahogo: franja de madrugada.

- Participación complementaria: los oyentes intervienen pero sin ocupar todo el tiempo de emisión (magacines)

- Relatar un caso propio o ajeno.

- Informar.

- Expresar una opinión.

- Denunciar un hecho o situación.

- Rectificar una información.

\subsubsection{Programas magazine}

Estos programas constituyen el género radiofónico más empleado en la actualidad. Están estructurados a partir de todos los demás géneros (en función de necesidades) y suelen combinar información y opinión de actualidad con entretenimiento y espectáculo. Son formatos flexibles, que permiten la incorporación de hechos noticiosos y suelen ocupar la franja matutina, vespertina y nocturna en las principales radios generalistas. También ha aumentado su presencia en la programación de fin de semana. Con el tiempo, los programas magazine han ido sustituyendo a la programación mosaico, y han formado una parrilla organizada por bloques que facilitan la acumulación de audiencias y su fidelización. Existe un gran protagonismo del/de la presentador/a. 


\subsection{Transformación y evolución de los géneros}

El género es algo dinámico, en constante evolución, basada en los siguientes factores:

1) Producción individual (búsqueda de originalidad, de nuevas fórmulas) unida a la figura del autor.

2) Condicionamientos impuestos por el aparato empresarial-productivo, empujado por su lógica de desarrollo (competitivo o institucional) a buscar nuevas vías para mantener su propia cuota de audiencia.

3) Intertextualidad, que atraviesa todos los sistemas de medios en su conjunto (convergencia).

Así, los géneros y formatos descritos sufren transformaciones. En la información, por ejemplo, se produce el infotainment, como resultado de la incorporación de cultura popular a los espacios informativos. En los géneros de ficción, por ejemplo, también se producen evoluciones, como por ejemplo en las sitcoms (domcoms, kidcoms, couplecoms, etc.) y también en el entretenimiento, como en los realities (reality concurso o los talent-shows).

\subsection{Géneros publicitarios para radio y televisión}

\subsubsection{Géneros publicitarios para radio}

- Bartering: un programa, microprograma o unidad móvil es producido y realizado por la firma publicitaria.

- Comunicados: textos publicitarios con tintes informativos.

- Concursos: microprogramas donde el contenido, los premios y la participación giran en torno al producto, patrocinador o anunciante.

- Cuñas: montajes grabados de palabra, música, efectos o combinación de estos elementos. Duración aproximada entre 10-15 segundos a 30 segundos.

- Cuñas promocionales o autopromoción (promos): cuñas no publicitarias que intentan promocionar un espacio, programación o emisora dentro o fuera de su franja horaria.

- Entrevista o consultorio: microespacio con esquema preguntas-respuestas donde interviene como entrevistado o especialista alguien que presenta la firma anunciante («entrevista simulada» con aparente carácter informativo).

- Flashes: cuñas no superiores a los 10 segundos.

- La guía comercial: lectura a dos voces de comunicados comerciales (a modo de titular informativo). 
- Menciones: textos publicitarios emitidos en directo, con o sin fondo musical, que se leen de forma aparentemente espontánea (contenido natural del programa).

- Microespacios o microprogramas: formato similar al patrocinio pero con duración de hasta cinco minutos (pueden ser mayores, de hasta media hora).

- Patrocinio: programa de carácter híbrido financiado por el anunciante pero que realiza la emisora.

- Prescripciones: menciones a modo de recomendaciones (presentador).

- Publirreportajes: similar al reportaje informativo, pero con la intencionalidad de vender un determinado producto.

- Unidades móviles: microprogramas o patrocinios realizados en el exterior (acontecimiento, promoción o venta de un producto); suelen ser «falsos directos» (diferido).

\subsubsection{Géneros publicitarios para televisión}

Podemos distinguir entre formatos convencionales:

- Spot:

- El spot sigue siendo la fórmula más empleada.

- Tiene una duración media de 20 segundos.

- Reubicación del spot tradicional:

+ Minicortes publicitarios.

+ Multipantalla.

+ Etc.

- Publirreportaje:

- Mayor duración que el spot.

Y formatos no convencionales:

- Patrocinio televisivo.

- Microprograma.

- Pantalla compartida.

- Bartering.

- Televenta.

- Informercials.

- Sobreimpresión.

- Virtual (círculo central en el estadio de fútbol).

- Product placement.

- Flash.

- Morphing. 


\section{Bloque 5 \\ Marco legal para \\ la programación}

Las principales normativas reguladoras son:

- La Ley 17/2006, de 5 de junio, de la radio y la televisión de titularidad estatal, que fue modificada por el Real Decreto-ley 15/2012, de 20 de abril, de modificación del régimen de administración de la Corporación RTVE, previsto en la Ley 17/2006, de 5 de junio.

- Ley 7/2010, de 31 de marzo, General del Audiovisual, que fue modificada por la Ley 6/2012, de 1 de agosto, de modificación de la Ley 7/2010, de 31 de marzo, General del Audiovisual, para flexibilizar los modos de gestión de los servicios públicos de comunicación audiovisual autonómicos.

Los principales aspectos de interés relacionados con la programación de contenidos se encuentran en las áreas de la contraprogramación, la promoción de contenidos, la regulación de la publicidad, la implantación y desarrollo de la TDT y la protección de las minorías. En este sentido, la normativa española basa gran parte de sus medidas en el marco europeo, establecido por la Directiva Televisión Sin Fronteras (TSF) de 1989 y la Directiva de Servicios de medios audiovisuales (2007).

a) Contraprogramación:

- Todos tienen el derecho a conocer la programación televisiva con una antelación suficiente, que en ningún caso será inferior a tres días. En el caso de la programación televisiva, además la programación se dará a conocer mediante una guía electrónica de programas, cuyo contenido gratuito básico deberá estar asimismo disponible en un servicio de información de programación en Internet mediante un archivo procesable por máquinas, de formato descargable, cuya estructura deberá ser de conocimiento público, y ubicado en una página web cuya disponibilidad será responsabilidad del prestador del servicio de comunicación audiovisual.

- La programación sólo podrá ser alterada por sucesos ajenos a la voluntad del prestador del servicio audiovisual o por acontecimientos sobrevenidos de interés informativo o de la programación en directo. 
- El servicio de información de la programación en Internet deberá disponer de mecanismos de aviso de que la programación ha sufrido modificaciones de última hora.

Su vulneración es considerada una infracción grave.

b) Promoción: La promoción de contenidos está orientada hacia la libre circulación de programas en el mercado europeo y al establecimiento de cuotas de emisión para las obras europeas. En el marco español, la promoción queda recogida en la Ley 7/2010, que establece:

- $51 \%$ emisión anual a obras europeas:

- 50\% a obras europeas (lenguas oficiales en España).

- $10 \%$ productores independientes del prestador de servicio (la mitad en los últimos cinco años).

- Contribución a la producción europea de: largometrajes, cortometrajes, películas y series para televisión, documental y productos de animación (menos siete años de producción).

- $5 \%$ ingresos anuales.

- $6 \%$ para titularidad pública (participación directa o derechos de explotación).

c) Publicidad:

- La radio y la televisión pública de titularidad estatal no admiten ninguna forma de publicidad y los prestadores de televisión de titularidad pública no podrán dedicar canales exclusivamente a emitir comunicación comercial.

- La duración: un $15 \%$ máximo del tiempo de transmisión diario y un $20 \%$ máximo dentro de un período determinado de una hora.

- Consideraciones éticas (sobre todo con respecto a los menores).

- El cumplimiento de determinados criterios sobre la publicidad para bebidas alcohólicas.

- La ubicación de publicidad en los medios españoles queda regulada de la siguiente forma:

- Televisión:

+ Doce minutos por hora. No incluye:

- Patrocinio.

- Emplazamiento.

- Autopromoción.

+ Diferenciados óptica y acústicamente (no superior al nivel medio del programa). 
+ Cada treinta minutos (películas e informativos).

+ Deportes: pausas o sin interrupción.

- Radio: libremente.

- El emplazamiento de producto está prohibido en la programación infantil.

d) Implantación y desarrollo de la TDT:

- El marco español:

- Ley 10/2005, de 14 de Junio, de Medidas Urgentes para el impulso de la televisión digital terrestre, de liberación de la televisión por cable y de fomento del pluralismo.

- Real Decreto 944/2005, de 29 de Julio, por el que se aprueba el Plan Técnico Nacional de la Televisión Digital Terrestre.

- 2009 Acuerdo del Consejo de Ministros por el que se aprueba el Plan nacional de Transición a la Televisión digital terrestre.

- Ley 7/2009, de 3 de julio, de medidas urgentes en materia de telecomunicaciones que regula la cobertura complementaria de los canales de TDT mediante, al menos, una plataforma común satelital.

- Real Decreto 365/2010, de 26 de marzo, por el que se regula la asignación de los múltiples de la televisión Digital Terrestre tras el cese de las emisiones de televisión terrestre con tecnología analógica.

- Ley 2/2011, de 4 de marzo, de Economía Sostenible, (LES) que prevé, en su artículo 51, que la banda de frecuencias de 790-892 MHz se destine principalmente para la prestación de servicios avanzados de comunicaciones electrónicas, en línea con los usos armonizados que se acuerden en la Unión Europea. La banda deberá quedar libre para poder ser asignada a sus nuevos usos antes del 2 de enero de 2015.

- También se ve afectada por el Real Decreto de reglamento sobre las condiciones básicas de accesibilidad en la sociedad de la información. En este sentido, la televisión digital debe procurar:

- Conversión de texto a voz para favorecer la navegabilidad de los menús.

- Aplicaciones de reconocimiento de voz.

- Ergonomía en los receptores de televisión digital.

- Aplicaciones de personalización para que, personas con discapacidad puedan configurar los receptores de televisión digital y, muy particularmente, los parámetros de visualización: tamaño y color de la fuente de letras, color de fondo, contraste y otros. 


\section{Bibliografía}

Alcudia, M. (2008): Nuevas perspectivas sobre los géneros radiofónicos. Madrid: Fragua.

Arana, Edorta (2011): Estrategias de programación televisiva. Madrid: Síntesis.

Palacio, Manuel y Contreras, José Miguel (2001): La programación de televisión. Madrid: Síntesis.

Álvarez Monzoncillo, José María (2011): La televisión etiquetada: nuevas audiencias, nuevos negocios. Madrid: Ariel.

Benito, A. (1991): Diccionario de ciencias y técnicas de la comunicación. Madrid: Paulinas.

Bigné, E. (1981): «La investigación de audiencias», en Ortega, E.: Manual de investigación comercial. Madrid: Pirámide.

Blanch, Margarita (1998): Cómo se miden las audiencias en radio. Barcelona: Cims.

BOE: ORDEN de 19 de diciembre de 1977 por la que se aprueba la Ordenanza Laboral de Trabajo para la Radiotelevisión Española. «ВоЕ» núm. 305. Ref: BOE-A-1977-30894 [Disposición derogada].

Bustamante, E. y Zallo, R. (1988): Las industrias culturales en España. Madrid: Akal.

Cebrián Herreros, M. (1978): Introducción al lenguaje de la televisión. Una perspectiva semiótica. Madrid: Pirámide.

Contreras, José Miguel y Palacio, Manuel (2001): La programación de televisión. Madrid: Síntesis.

CorTés, J. A. (1989): «Tipología de la comunicación», en VII Jornadas Universidad e Información. Universidad de Sevilla. Conferencia.

- (1999): La estrategia de la seducción. La programación en la neotelevisión. Pamplona: Eunsa.

Dagnaud, Monique (1990): «Profession: Programmateur», en Mediaspouvoirs, $\mathrm{X}$-XII.

De la Mota, I. (1998): Diccionario de la comunicación. Madrid: Paraninfo.

Eastman, Susan Tayler y Ferguson, Douglas A. (2013): Media programming: strategies and practices. Berlmont: Wadsworth/Cengage Learning.

Ellis, J. (2000): «Scheduling: the last creative act in televisión?», en Media Culture and Society, 22: 25-38.

FAus, A. (1995): La era audiovisual. Historia de los primeros cien años de la radio y la televisión. Barcelona: Ediciones Internacionales Universitarias.

Fergusson, D., Meyer, T. y Eastman, S. (2009): «Program and Audience Research», en Eastmant, S. T. y Ferguson, A. A., Media Programming. Strategies and Practices. Boston: Thomson Wadsworth.

Francès, Miquel; GavaldÀ, Josep y Peris, Àlvar (coords.) (2014): La televisión de la crisis ante el abismo digital. Barcelona: Gedisa.

IZQUIERDO-CASTILlO, JÉSSICA (2014): «La programación en la televisión online: nuevas estrategias para nuevos escenarios», en Francès, Miquel; GaVAldÀ, JoSEP y PERIS, ÀlVAR (coords.): La televisión de la crisis ante el abismo digital. Barcelona: Gedisa. 
IZQUIERDO-CASTILlo, JÉSSICA (2014): «La evolución del sector televisivo: un oligopolio frente a Internet». En Historia y Comunicación Social, vol. 19, pp. 735-745.

Jauset, J. M. (2000): La investigación de audiencias en televisión. Barcelona: Paidós.

Lasswell, H. D. (1948): The Structure and Function of Communication in Society. Nueva York: Harper \& Bros.

Martí, Josep María (2000): De la idea a l'antena. Tècniques de programació radiofónica. Barcelona: Pòrtic.

Martínez-Costa, M. P. y Moreno, E. (2004): Programación radiofónica. Arte y técnica del diálogo entre la radio y su audiencia. Madrid: Ariel.

Martínez-Costa, M. P. y Díez, J. R. (2005): Lenguaje, géneros y programas de radio. Introducción a la narrativa radiofónica. Navarra: Eunsa.

Ortiz, M. A. y Volpini, F. (1995): Diseño de programas en radio. Guiones, géneros y fórmulas. Barcelona: Paidós.

Palacio, M. (1989): Estructura de la programación de Radio y Televisión. Madrid: Universidad Complutense de Madrid.

Paterson, R. (1990): «A Suitable Schedule for the Family», en Goodwing, A. y Whannel, G. (ed.): Understanding Television. Londres: Routledge.

Pedrero, L. M. (2000): La radio musical en España. Madrid: Historia y análisis, IORTV.

Prado, Emilio y Delgado, Matilde (2010): «La televisión generalista en la era digital. Tendencias internacionales de programación», en Telos (Cuadernos de Comunicación e Innovación), ISSN: 0213-084X, pp. 1/14.

RYAN, M. L. (1988): Hacia una teoría de la competencia genérica. En: GALLARDO, G. (ed.): Teoría de los géneros literarios. Madrid: Arco/Libros.

SCOLARI, CARlos (2008): «Hacia la hipertelevisión. Los primeros síntomas de una nueva configuración del dispositivo televisivo», en Logos. Diálogos de la comunicación, n. ${ }^{\circ} 77$.

VvaA (2009): Hacia una nuevo modelo televisivo: contenidos para la televisión digital. Barcelona: Gedisa.

Wolf, Mauro (1984): «Géneros y televisión», en Anàlisi: quaderns de comunicación i cultura, 9. 